\title{
Short-Term Growth in Children with Congenital Adrenal Hyperplasia
}

\author{
Kaur Liivak ${ }^{a}$ Peter J. Foster ${ }^{b}$ Nandu Thalange ${ }^{c}$ Vallo Tillmann ${ }^{a}$ \\ a Department of Paediatrics, University of Tartu, Tartu, Estonia; ${ }^{b}$ University of Manchester, School of Mathematics, \\ Manchester, and 'Jenny Lind Children's Department, Norfolk and Norwich University Hospital, Norwich, UK
}

\section{Key Words}

Short-term growth $\cdot$ Congenital adrenal hyperplasia $\cdot$

Impaired height $\cdot$ Growth spurts

\begin{abstract}
Objective: To describe short-term growth patterns in children with congenital adrenal hyperplasia (CAH). Methods: Height was measured daily in 5 children (1 boy) aged 3.9-9.7 years over 9-16 months. Kernel regression analysis was used to characterise short-term growth. The results were compared with data from 43 normal prepubertal children. Results: Growth was characterised by growth spurts with intervening periods of no discernible growth (stasis). Height gain was positively correlated with the mean amplitude of growth spurts $(r=0.9, p<0.05)$. Patients with $C A H$ spent significantly less time in stasis than normal children $(5 \pm 4.8 \mathrm{vs}$. $11.4 \pm$ $7.2 \%$ of study period; $p<0.05$ ), the mean length of growth spurts was significantly longer (110.4 \pm 28.3 vs. $54.0 \pm 13.1$ days; $\mathrm{p}<0.05)$ and the mean amplitude significantly lower $(0.022 \pm 0.008$ vs. $0.037 \pm 0.001 \mathrm{~cm} /$ day; $\mathrm{p}<0.01)$. Conclusions: Compared with normal controls, short-term growth in children with $\mathrm{CAH}$ is characterised by long-duration low amplitude growth spurts with reduced periods of growth stasis. Better growth was correlated with the amplitude of growth spurts. The relatively smooth short-term growth in children with $\mathrm{CAH}$ suggests that if significant variations in growth rate are seen, they are more likely to be a consequence of under- or over-treatment rather than non-linear growth itself.

Copyright $\odot 2009$ S. Karger AG, Basel
\end{abstract}

\section{Introduction}

Achieving normal adult height is one of the most important goals in treatment of children with congenital adrenal hyperplasia (CAH); hence growth monitoring is an essential part of the follow-up of these patients. Monitoring at 3- to 4-month intervals is common practice. However, growth over short periods of time is non-linear [1]. This non-linear growth, compounded by inherent measurement error, means that growth rates vary markedly between successive measurements, complicating the clinical assessment of the child with CAH.

While investigators agree that growth over short periods is non-linear, the exact pattern is disputed [2]. Our growth model, based on a study of 43 normal children, describes growth as a non-linear process composed of growth spurts lasting, on average, 8 weeks separated by a period of very slow growth or stasis [3]. In the same cohort, we also found that the pattern of short-term changes in height and weight within a year is an important determinant of growth [4]. Children with growth hormone deficiency and Turner syndrome have different patterns of short-term growth [5], compared with normal subjects, with growth spurts of low amplitude and increased time spent in stasis.

Despite more than 50 years experience with glucocorticoid treatment, the final adult height in patients with $\mathrm{CAH}$ remains below the parental target height [6-9]. Reduced adult height may be a consequence of under-treatment, resulting in adrenal androgen excess (commonly

\section{KARGER}

Fax +4161306 1234 E-Mail karger@karger.ch www.karger.com

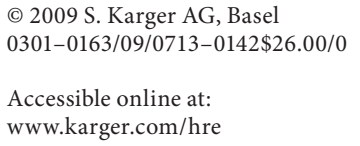

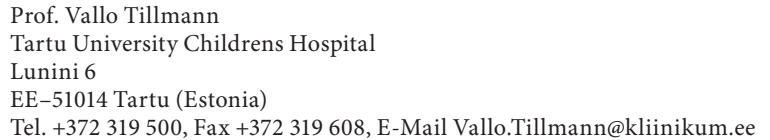


Table 1. Auxological and clinical data of 5 children with $\mathrm{CAH}$

\begin{tabular}{|c|c|c|c|c|c|c|c|}
\hline & \multicolumn{5}{|c|}{ Subject } & \multirow[t]{2}{*}{ Mean } & \multirow[t]{2}{*}{ Normal } \\
\hline & 1 & 2 & 3 & 4 & 5 & & \\
\hline Age, years & 5.9 & 3.9 & 4.3 & 5.2 & 9.7 & 5.8 & $5.7-7.7$ \\
\hline Sex & $\mathrm{F}$ & $\mathrm{F}$ & M & $\mathrm{F}$ & $\mathrm{F}$ & & \\
\hline Time of the study, days & 255 & 466 & 267 & 284 & 304 & 315 & \\
\hline Height $1, \mathrm{~cm}$ & 107.1 & 100.6 & 96.2 & 100 & 140.6 & 108.9 & \\
\hline Height $2, \mathrm{~cm}$ & 110.9 & 114.6 & 103.2 & 106.6 & 144.4 & 115.9 & \\
\hline$\Delta$ Height, $\mathrm{cm}$ & 3.9 & 14.0 & 7.0 & 6.6 & 3.8 & 7.06 & \\
\hline Height SDS 1 & -2.0 & -0.15 & -1.9 & -2.11 & -0.42 & -1.15 & $0.0(-2.9$ to +2.3$)$ \\
\hline Height SDS 2 & -1.78 & 0.75 & -1.52 & -2.08 & 0.15 & -0.89 & $0.2(-2.7$ to +2.5$)$ \\
\hline$\Delta$ Height SDS & 0.22 & 0.9 & 0.45 & 0.03 & -0.27 & 0.26 & $0.2(-0.2$ to +0.7$)$ \\
\hline Target height SDS & -0.65 & -0.47 & 0.76 & 1.33 & 1.33 & 0.46 & \\
\hline$\Delta \mathrm{BA} /$ year & -0.5 & +1.4 & +0.7 & -0.1 & -0.5 & +1.0 & \\
\hline Hydrocortisone, $\mathrm{mg} / \mathrm{m}^{2} /$ day & 15.9 & 23.9 & 24.6 & 21.9 & 22.9 & 21.8 & \\
\hline Fludrocortisone daily, mg/day & 0.05 & 0.1 & 0.175 & 0.1 & 0.1 & 0.1 & \\
\hline Mean 17-OHP, nmol/l & 56 & 7 & 0.2 & 67 & 63 & 39 & \\
\hline Mean amplitude of growth spurt, $\mathrm{cm} /$ day & 0.016 & 0.032 & 0.028 & 0.023 & 0.013 & $0.022^{\mathrm{a}}$ & $0.037(0.025-0.09)$ \\
\hline Mean length of growth spurt, days & 74 & 144 & 128 & 116 & 90 & $110.4^{\mathrm{b}}$ & $54(37-96)$ \\
\hline Time in stasis, $\%$ & 10 & 6 & 1 & 0 & 10 & $5.4^{\mathrm{b}}$ & $11(6-16)$ \\
\hline Stasis & 2 & 1 & 1 & 0 & 2 & & \\
\hline Spurts & 3 & 3 & 2 & 3 & 3 & & \\
\hline
\end{tabular}

Normal values in table are from 43 healthy children [4]. ${ }^{\mathrm{a}} \mathrm{p}<0.01,{ }^{\mathrm{b}} \mathrm{p}<0.05$ vs. controls.

due to non-compliance) with increased growth velocity, accelerated skeletal maturation and early epiphyseal fusion, or over-treatment with glucocorticoids, or with abnormal salt metabolism during infancy [10]. Achieving satisfactory ACTH suppression with glucocorticoids, whilst permitting optimal growth is often difficult to achieve, even with optimal timing and frequency of hydrocortisone administration, with detrimental effects on final height [7].

There are no published data about short-term growth in children with CAH. We have now studied the shortterm changes in growth velocity in a small group of children with $\mathrm{CAH}$ and compared their growth characteristics with those of normal children. Knowing the pattern of short-term growth will help to clarify whether temporal accelerations or decelerations in growth rate are more likely caused by over- or under-treatment, or non-linear growth itself. It may also cast light on the mechanism of reduced final height in patients with $\mathrm{CAH}$ similar to the study in normal children where shorter children were found to have growth spurts of long duration [4].

\section{Patients and Methods}

\section{Patients}

All six prepubertal patients ( 2 boys and 4 girls) with salt-wasting $\mathrm{CAH}$ followed at the Tartu University Children's Hospital agreed to participate in the study. Five patients completed the study. In one boy $1 / 3$ of daily measurements were missing and therefore excluded from analysis. The diagnosis of $\mathrm{CAH}$ secondary to 21-OHD was confirmed by the clinical picture, elevated serum 17-hydroxyprogesterone (17-OHP) level and mutation analysis of the CYP21A2 gene [11]. The genotypes of our patients were: subject $1-8 \mathrm{bp} \mathrm{del/chimeric} \mathrm{(common} \mathrm{deletion} \mathrm{or} \mathrm{conver-}$ sion), subject 2 - p.Gln318X/chimeric, subject 3 - In 2 splice/chimeric, subjects 4 and 5 - p.Arg356Trp (hemi/homozygous genotype, i.e. other large deletion or 2 copies of the mutation). The mean age at diagnosis was 5 days. The mean age at the beginning of the study was 5.8 years (range 3.9-9.7). All patients received hydrocortisone 3 times daily with higher doses in the morning, and fludrocortisone once daily. The 17-OHP values were taken in the morning (between 8 and 10 a.m.) at 3-month intervals over the study period and presented as a mean value. Bone age (BA), calculated by the RUS method [12], was taken from the case notes at the nearest time point $\left(\mathrm{BA}_{1}\right)$ before (chronological age $\left.\mathrm{CA}_{1}\right)$ and after the study $\left(\mathrm{BA}_{2}\right.$ and $\left.\mathrm{CA}_{2}\right)$. To estimate the possible effect of $\mathrm{BA}$ maturation on growth, change in $\mathrm{BA}$ per year $(\triangle \mathrm{BA} /$ year $)$ was calculated: $\Delta \mathrm{BA} /$ year $=\left(\mathrm{BA}_{2}-\mathrm{CA}_{2}\right)-\left(\mathrm{BA}_{1}-\mathrm{CA}_{1}\right) /\left(\mathrm{CA}_{2}-\mathrm{CA}_{1}\right)$. Thus, positive $\triangle \mathrm{BA} /$ year indicates increased $\mathrm{BA}$ maturation. Auxological and clinical characteristics are given in table 1 . The 
study was approved by the Tartu University Ethics Committee. Informed consent was obtained from parents of all patients.

\section{Growth Measurements}

All subjects were measured daily by one parent before bedtime over the study period (260-470 days), using the stretched technique (gentle upward pressure on the mastoid processes). Triplicate height measurements were taken on each occasion using a Raven Minimeter. The mean of the triplicate measurements was used in the analysis. In total, 4,728 height measurements were taken from 5 patients. There was a 2 -week learning period for measuring technique. At the beginning of the study, each child had nine 'blind' triplicate measurements taken by his/her parent who later undertook all the measurements. The measurement error expressed as a standard deviation of the differences between these nine 'blind' triplicate measurements was between 0.08 and $0.14 \mathrm{~cm}$.

\section{Statistical Analysis}

Height standard deviation score (SDS) at the beginning of the study (SDS1) and at the end of the study (SDS2) for each patient was calculated from Estonian growth standards [13]. To obtain a better estimate of growth and growth velocity as function of time, we constructed smooth estimates of individual height and height velocity profiles using locally weighted, least squares, kernel regression analysis [14], with a bandwidth of 20 days for the height regression and 60 days for the velocity regression. The bandwidths were determined by a predicted squared error criterion [15], so as to minimise error. Growth spurts were identified by using local maxima and minima in the velocity curves. In keeping with our previous studies $[3,4]$ growth stasis was defined as any period in which the height velocity curve fell below $0.007 \mathrm{~cm} /$ day $(<0.5 \mathrm{~mm} /$ week). Characteristics defined from the height velocity curves included: (1) the number of growth spurts and stasis; (2) the mean length (days) and amplitude (cm/day) of the growth spurts; (3) the time spent in stasis (days) as a percentage of the study period (days). Characteristics of the growth velocity curves were compared with those found in our previous study of 43 normal prepubertal children (17 boys, 26 girls) [4]. The mean age of controls was 6.7 years (range 5.7-7.7) and mean height SDS calculated from the UK standards [16] at the beginning of the study was 0.0 (range -2.9 to 2.3 ). A two-sample t test was used to compare data with controls. $\mathrm{p}<0.05$ was considered to be statistically significant.

\section{Results}

\section{Height and Height Velocity}

Original measurements and estimated regression curves for height of patient 1 and height velocity for all 5 patients are given in figure 1. Four patients had a biphasic growth pattern characterised by growth peaks and periods of very slow growth or stasis. The only child who did not have any stasis (No. 4) was the shortest (height SDS -2.08) and had the highest mean 17-OHP level over the study period (mean $67 \mathrm{nmol} / \mathrm{l})$. In spite of the relatively high hydrocortisone dose, the biochemical control expressed as a mean serum 17-OHP value over the study period in 3 patients was not good. However, growth over the study period in these 3 patients was normal (mean $\Delta$ height SDS -0.02). In the other 2 patients with normal 17-OHP values, despite high hydrocortisone doses, their $\Delta \mathrm{BA} /$ year was positive i.e. BA maturation was quicker than chronological age development and also their height gain over the study period was increased, implying some degree of non-compliance.

Patients with CAH spent significantly less time in stasis than normal children (mean $5 \pm 4.8$ vs. $11.4 \pm 7.2 \%$ of study period; $\mathrm{p}<0.05$ ). The mean length of height velocity peaks was significantly longer $(110.4 \pm 28.3 \mathrm{vs}$. $54.0 \pm 13.1$ days; $\mathrm{p}<0.05)$ and the mean amplitude of spurt was significantly lower $(0.022 \pm 0.008$ vs. $0.037 \pm$ $0.001 \mathrm{~cm} /$ day; $\mathrm{p}<0.01)$ than those in normal children. Height gain over the study period ( $\Delta$ height SDS) was positively correlated to the mean amplitude of growth spurts $(r=0.9, p<0.05)$.

\section{Discussion}

This is the first study describing short-term growth in children with CAH. As in our previous studies $[4,5]$, we used a non-parametric technique to generate growth curves to avoid imposing a particular form to the growth process, which would result from the use of a linear, polynomial or step function. However such curves do not adequately define the dynamic growth process: the smoothing component tends to mask abrupt changes in height. Therefore, we constructed height velocity curves to describe the characteristics (e.g. length, amplitude) of the growth process. Curve characteristics were compared with data from 43 normal prepubertal children [4] constructed using the same methodology and with the same bandwidth. There is no reason to consider that the essential character of non-linear growth is different in children in Estonia compared with those living in Manchester, UK. This is further supported by the observation that 2 Estonian boys measured daily over a year [17] showed similar growth pattern to those seen in the UK study [3]. Measurement error calculated by the same methodology in 2 observers who did the measurements in control children was similar $(0.13-0.15 \mathrm{~cm})$ to that seen in this study where growth was measured by parents. Thus, the comparison to that control group is valid.

All 5 patients with CAH had growth spurts; 4 had 1 or 2 periods of slow growth or stasis, but one subject, with 


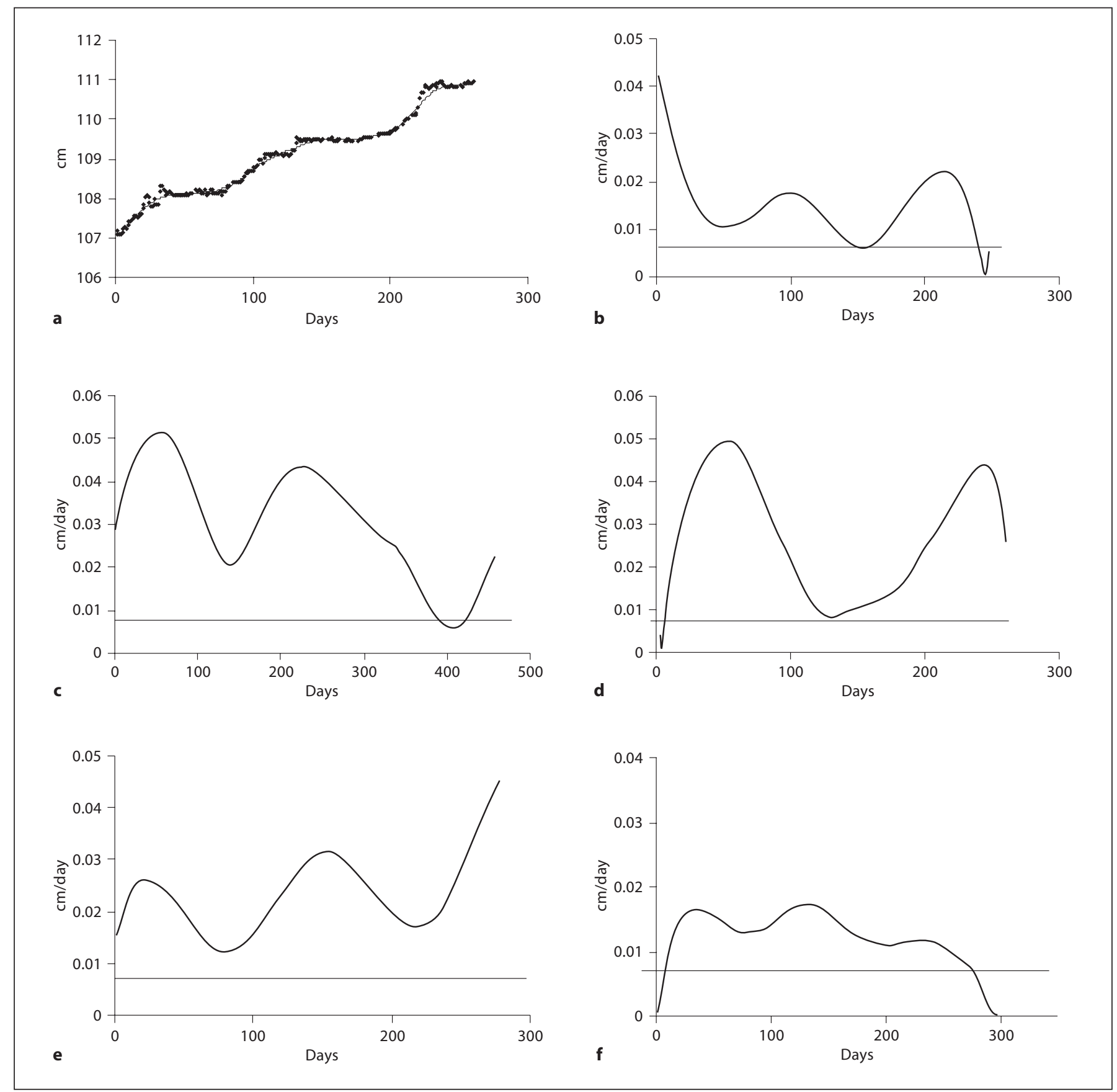

Fig. 1. Original height measurements (dots; a) and estimated height and height velocity curves (lines; b) in subject 1 and estimated height velocity curves (lines) in subjects 2 (c), 3 (d), 4 (e) and 5 (f). Growth stasis was defined as any period in which the height velocity curve fell below $0.007 \mathrm{~cm} /$ day.

poor control had no discernible period of stasis. The mean amplitude of growth spurt in all 5 patients was significantly lower than in normal children, and in 3 it was below the lowest value seen in normal children $(<0.025$ $\mathrm{cm} /$ day). The mean amplitude of the other 2 subjects was below the mean for normal children. The mean length of growth spurts was twice that seen in normal children (110 days vs. 54 days). In healthy children, it is known that 
the length and not the amplitude is a significant determinant of child's height [4]. Thus, these long-lasting, lowamplitude growth spurts may ultimately result in impaired final height. The two patients with the longest growth spurts (No. 2 and 3) showed rapid growth and BA maturation despite high hydrocortisone doses, implying non-compliance with treatment, and are consequently at high risk of impaired final height. We were surprised that children with $\mathrm{CAH}$ spent less time in stasis, in contrast to children with growth hormone deficiency and Turner syndrome, who spent more time in stasis [5]. Thus, children with CAH grow with a relatively steady growth rate, with only small fluctuations in their growth velocity. Our patients (except patient 2) with CAH grew with normal growth rate, over the period of the study (mean $\Delta$ height SDS +0.26), similar to that seen in normal children ( $\Delta$ height SDS +0.20$)$ [4]. In that group, growth through the year was positively influenced by the mean amplitude of height velocity peaks. Similar correlation was also seen in this study. Growth over the study period ( $\Delta$ height SDS) was positively correlated to the mean amplitude of growth spurts $(\mathrm{r}=0.9, \mathrm{p}=0.037)$. This indicates that children who grow faster have higher amplitude growth spurts.

The weakness of the study is a small number of patients. However, it was big enough to detect statistically significant differences in 3 curve characteristics, one of them (mean amplitude of growth spurt) with high probability ( $p<0.01)$. Thus, this small group was sufficient to describe short-term growth pattern in children with $\mathrm{CAH}$ by comparing the curve characteristics to those seen in normal children. However, the number of patients is too small to assess the impact of biochemical control or hydrocortisone dose on that growth pattern. Further studies of a larger group of patients are needed to confirm the growth pattern detected and to define the relative contribution of good and poor control of the disease.

The observed pattern of growth in children with $\mathrm{CAH}$ is similar to shorter children within the cohort of normal controls, who also exhibited longer growth spurts [4]. The physiological basis for this alteration in normal growth is unknown. One explanation may be that children with $\mathrm{CAH}$ compared to normal children have a more regular pattern of growth hormone $(\mathrm{GH})$ secretion [18] known to be associated with poorer growth [19], which in turn is likely to be consequent of hydrocortisone treatment [18]. Altered circadian rhythmicity of GH secretion which is glucocorticoid independent may be another possible explanation [20].

Our study has also a clinical implication. Growth monitoring, at 3-4 monthly intervals, is an important part of the follow-up of children with CAH. Small fluctuations in growth rate are interpretable either as a consequence of over- or under-treatment, or the underlying non-linear growth process. Our data indicate that the normal short-term growth pattern of children with $\mathrm{CAH}$ is 'damped', with reduced amplitude growth spurts of increased length, and consequently that significant variations in growth rate are more likely to reflect treatment effects, than to be a consequence of non-linear growth itself.

\section{Conclusions}

Short-term growth in children with CAH compared to normal children is a relatively steady process characterised by low-amplitude fluctuations in the velocity of growth spurts. Growth within the year is positively related to the mean amplitude of individual growth spurts, but the amplitude is reduced compared with normal children. Relatively smooth growth in children with $\mathrm{CAH}$ suggests that any short-term acceleration or deceleration in their growth rate is most likely due to under- or overtreatment rather than the non-linear growth pattern itself.

\section{Acknowledgements}

The study was funded by Estonian Science Foundation Grant No. 5835 and Grant No. 2695 of the Estonian Ministry of Education and Science.

References growth. Horm Res 1998;49:53-64

2 Wales JK, Gibson AT: Short-term growth: rhythms, chaos, or noise? Arch Dis Child 1994;71:84-89.

-3 Thalange NKS, Foster PJ, Gill MS, Price DA, Clayton PE: A model of normal prepubertal growth. Arch Dis Child 1996;75:427-423.

-4 Tillmann V, Thalange NKS, Foster PJ, Gill MS, Price DA, Clayton PE: The relationship between stature, growth and short-term changes in height and weight in normal prepubertal children. Pediatr Res 1998;44:882886

$\checkmark 5$ Tillmann V, Foster PJ, Gill MS, Price DA, Clayton PE: Short-term changes in children with growth disorders. Ann Hum Biol 2002; 29:89-104.

-6 Jääskelainen J, Voutilainen R: Growth of patients with 21-hydroxylase deficiency: an analysis of the factors influencing adult height. Pediatr Res 1997;41:30-33. 
7 Eugster EA, DiMeglio LA, Wright JC, Freidenberg GR, Seshadri R, Pescovitz OH: Height outcome in congenital adrenal hyperplasia caused by 21-hydroxylase deficiency: a meta-analysis. J Pediatr 2001;138:2632 .

8 Carbera MS, Vogiatzi MG, New MI: Long term outcome in adult males with classic congenital adrenal hyperplasia. J Clin Endocrinol Metab 2001;86:3070-3078.

$\checkmark 9$ Manoli I, Kanaka-Gantenbein Ch, Voutetakis A, Maniati-Christidi M, Dacou-Voutetakis C: Early growth, pubertal development, body mass index and final height of patients with congenital adrenal hyperplasia: factors involving the outcome. Clin Endocrinol 2002;57:669-676.

-10 Balsamo A, Cicognani A, Baldazzi L, Barbaro M, Baronio F, Gennari M, Bal M, Cassio A, Kontaxaki K, Cacciari E: CYP21 genotype, adult height and pubertal development in 55 patients treated for 21-hydroxylase deficiency. J Clin Endocrinol Metab 2003;88: 5680-5688.
11 Liivak K, Tobi S, Schlecht H, Tillmann V: Incidence of classical 21-hydroxylase deficiency and distribution of CYP21A2 mutations in Estonia. Horm Res 2008;69:227-232.

12 Tanner JM, Healy MYR, Goldstein H, Ameron N: Assessment of Skeletal Maturation and prediction of adult height (TW3 method), ed 3. London, Saunders, 2001.

13 Silla R, Teoste M: Eesti Noorsoo Tervis. Tallinn, Valgus, 1989.

14 Rubert D, Wand P: Multivariate locally weighted least squares regression. Ann Stat 1994;22:1346-1370.

15 Muller H-G: Nonparametric Analysis of Longitudinal Data. Kernel Regression. Lecture Notes in Statistics 46. Berlin, Springer, 1987, pp 115-207.

16 Freeman JV, Cole TJ, Chinn S, Jones PRM, White EM, Preece MA: Cross-sectional stature and weight reference curves for the UK, 1990. Arch Dis Child 1995;73:17-24.
17 Tillmann V, Clayton PE: Diurnal variation in height and the reliability of height measurements using stretched and unstretched techniques in the evaluation of short-term growth. Ann Hum Biol 2001;28:195-206.

18 Charmandary E, Pincus SM, Matthews DR, Johnston A, Brook CGD, Hindmarsh PC: Oral hydrocortisone administration in children with classic 21-hydroxylase deficiency leads to more synchronous joint GH and cortisol secretion. J Clin Endocrinol Metab 2002;87:2238-2244.

19 Gill MS, Tillmann V, Veldhuis JD, Clayton P: Patterns of GH output and their synchrony with short-term height increments influence stature and growth performance in normal children. J Clin Endocrinol Metab 2001;86: 5860-5863.

20 Barkan AL, Demott-Friberg R, Samuels MH: Growth hormone $(\mathrm{GH})$ secretion in primary adrenal insufficiency: effects of cortisone withdrawal and patterned replacement on GH pulsatility and circadian rhytmicity. $\mathrm{Pi}$ tuitary 2000;3:175-179. 